\title{
Double stenting for malignant oesophago-respiratory fistula
}

\author{
Janusz Włodarczyk, Jarosław Kużdżał \\ Department of Thoracic Surgery, Jagiellonian University Collegium Medicum, John Paul II Hospital, Krakow, Poland
}

Videosurgery Miniinv 2016; 11 (3): 214-221

DOI: $10.5114 /$ wiitm.2016.62042

\begin{abstract}
Introduction: The close anatomical relationship between the oesophagus and bronchial tree results in formation of an oesophago-respiratory fistula in a subset of patients with advanced oesophageal or lung cancer. In those patients stenting of both the oesophagus and tracheobronchial tree is a valid option of palliative treatment.

Aim: To determine the effectiveness, tolerance, quality of life, safety and survival after double stenting procedures. Material and methods: Retrospective analysis of a prospectively collected database was performed, concerning consecutive patients with oesophago-respiratory fistulas treated with double stenting. In all patients the degree of dysphagia, respiratory function before and after the procedure, and quality of life were evaluated. Partially covered oesophageal self-expanding metallic stents (PCESEMS) were used for oesophageal stenting, and silicone Y-type or partially covered self-expanding bronchial and tracheal stents (PCASEMS) were used to restore airway patency.

Results: Between 2003 and 2015, 31 patients underwent double stenting due to oesophago-respiratory fistulas. Twenty-nine patients were diagnosed with oesophageal squamous cell carcinoma and 2 with bronchial carcinoma. In all patients, improvement in the general condition and quality of life was observed after airway patency restoration. Two patients required mechanical ventilation due to respiratory failure immediately after the procedure. Seven patients with oesophageal fistulas died because of bleeding in the long-term follow-up. Four patients required endoscopic re-intervention. Mean survival time was 67.1 days.

Conclusions: Double stenting is an effective procedure improving patients' quality of life. However, life-threatening complications can occur.
\end{abstract}

Key words: double stenting, oesophageal carcinoma, bronchial carcinoma, fistula.

\section{Introduction}

Oesophageal fistula to the airway or mediastinum is considered a severe complication of oesophageal or bronchial carcinoma. Its occurrence is associated with the anatomical relationship between the oesophagus and the trachea and main bronchi. It is estimated that during the course of inoperable oesophageal carcinoma, airway compression is observed in $30 \%$ of patients, while in the cases of $10 \%$ of patients with bronchial carcinoma oesophageal stenosis and progressive dysphagia may be seen [1, 2]. Self-ex- panding oesophageal and bronchial prostheses, as well as bifurcated Y-type silicone prostheses, may be used as a means of palliation in these patients, as well as chemo- and/or radiotherapy [3-5].

\section{Aim}

The aim of the study was to determine the effectiveness, tolerance, quality of life, safety and survival after double stenting procedures as a means of palliation in patients with a oesophago-respiratory fistula.

\section{Address for correspondence}

Janusz Włodarczyk MD, PhD, Department of Thoracic Surgery, John Paul II Hospital, 80 Pradnicka St, 31-202 Krakow, Poland,

phone: +48 691893 853, fax: +48 1261434 31, e-mail: jr.wlodarczyk@gmail.com 


\section{Material and methods}

\section{Clinical characteristics}

The analysis concerned 31 patients with inoperable oesophageal and bronchial carcinoma (24 men and 7 women), aged 31-82 years, who underwent double stenting of the oesophagus and bronchial tree between 2003 and 2015. In all patients the degree of dysphagia and respiratory function before and after the procedure were evaluated (Table I). Dysphagia was classified using a four-point scale [6]: 0 - able to swallow all solid foods without dysphagia; 1 - able to swallow solid foods with some difficulty; 2 - able to swallow soft or semisoft foods only; 3 - able to swallow liquids or saliva.

The degree of airway obstruction and impaired respiratory function was evaluated using an origi- nally designed four-point scale: 0 - airway stenosis < 30\%, without dyspnoea; 1 - airway stenosis 30$50 \%$, dyspnoea while walking; 2 - airway stenosis 50-70\%, dyspnoea after several minutes of marching; 3 - subtotal airway stenosis > 70\%, dyspnoea at rest.

Patients with oesophageal fistula were classified using an originally designed scale according to their location:

- type I - oesophago-mediastinal fistula without bronchial penetration;

- type II - oesophageal fistula penetrating to the trachea;

- type III - oesophageal fistula penetrating to the bifurcation or main bronchi.

The patients' general condition and quality of life, before and after stenting, was assessed according

Table I. Demographic and clinical data of patients with oesophago-respiratory fistula

\begin{tabular}{|c|c|c|c|c|}
\hline \multirow[t]{2}{*}{ Parameter } & \multirow[t]{2}{*}{$N$} & \multicolumn{3}{|c|}{ Type of fistulas } \\
\hline & & Type I & Type II & Type III \\
\hline Patients & 31 & 5 & 9 & 17 \\
\hline Mean age (range) [years] & & $52.0(47-58)$ & $53.6(31-67)$ & $64.8(42-82)$ \\
\hline Male/female & & $5 / 0$ & $6 / 3$ & $15 / 2$ \\
\hline \multicolumn{5}{|l|}{ Type of cancer: } \\
\hline Oesophageal & 29 & 4 & 9 & 16 \\
\hline NSCLC & 2 & 1 & 0 & 1 \\
\hline \multicolumn{5}{|l|}{ Length of infiltration in oesophagus (mean) [cm]: } \\
\hline Oesophagus & & $5.75(4-8)$ & $6.57(4-12)$ & $6.13(3-10)$ \\
\hline NSCLC & & 3 & 4 & 4 \\
\hline \multicolumn{5}{|l|}{ Location of stricture in the airway > 30\%: } \\
\hline Tracheal & & 1 & 5 & 2 \\
\hline Carina & & 2 & 4 & 13 \\
\hline $\mathrm{LMBr}$ & & 2 & 0 & 2 \\
\hline \multicolumn{5}{|l|}{ Type of prosthesis: } \\
\hline PCESEMS oesophageal + Y silicon airway stent & & 4 & 4 & 15 \\
\hline PCESEMS (oesophageal) + PCASEMS (tracheal) & & 1 & 5 & 0 \\
\hline PCESEMS (oesophageal) + PCASEMS (bronchial) & & 0 & 0 & 2 \\
\hline \multicolumn{5}{|l|}{ Adjuvant therapy: } \\
\hline $\mathrm{CTH}$ & & 4 & 5 & 7 \\
\hline $\mathrm{CTH}+\mathrm{RTH}$ & & 2 & 3 & 0 \\
\hline
\end{tabular}

NSCLC - non-small-cell lung cancer, LMBr - left main bronchus, PCESEMS - partially covered oesophageal self-expanding metallic stents, PCASEMS - partially covered self-expanding metallic stents (tracheal and bronchial), CTH - chemotherapy, RTH - radiotherapy. 
to the Karnofsky scale [7]. Patients with < 40 points were excluded from the study.

\section{Criteria for double stenting}

Patients with inoperable oesophageal or bronchial carcinoma with oesophago-airway fistulas were qualified for double stenting. Prior to the planned procedure the following tests were performed: chest radiogram, oesophageal and bronchial endoscopy, and abdominal and chest computed tomography (CT).

Criteria for double stenting included: tumour located $\geq 2 \mathrm{~cm}$ from the upper oesophageal sphincter; endoscopically confirmed fistula penetrating the mediastinum or bronchial tree; airway compression or infiltration posing a risk of severe airway compromise after expansion of the oesophageal stent.

\section{Stenting technique}

The procedure was performed using general anaesthesia. Routinely, airway stenting was performed
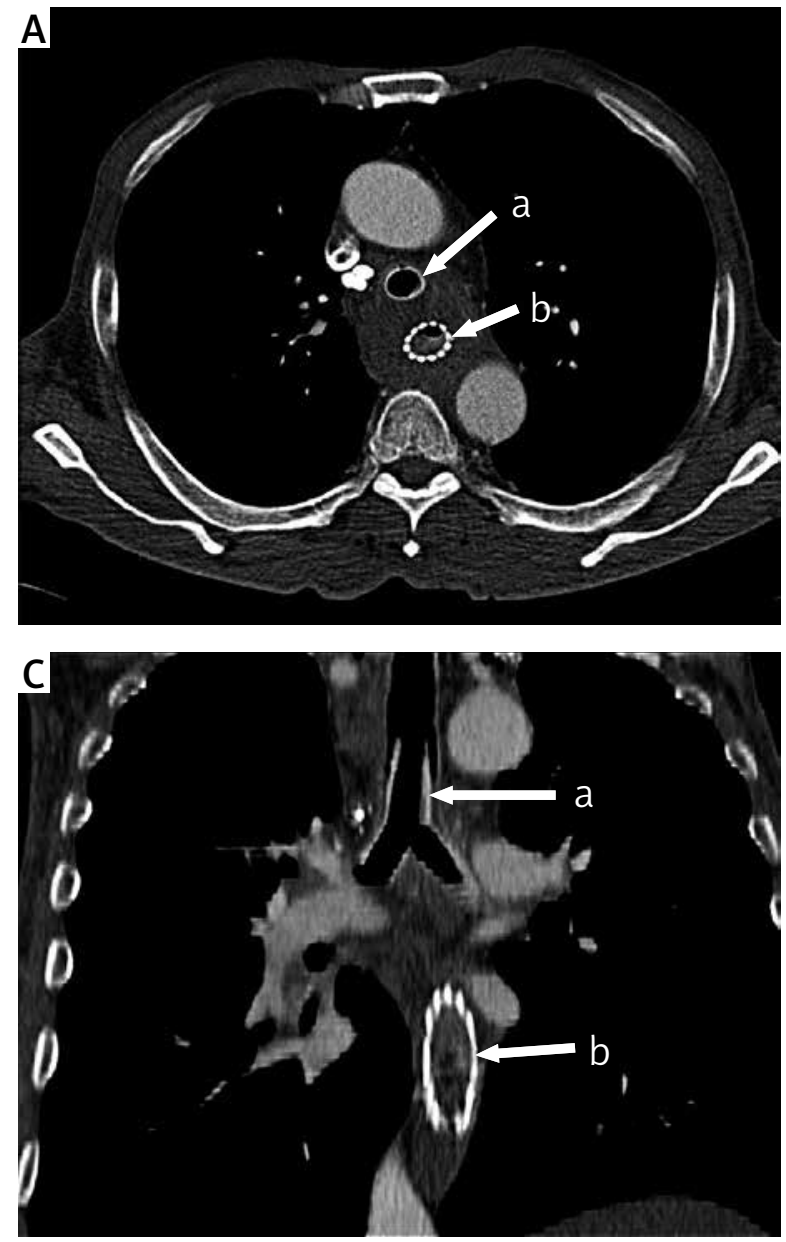

first to avoid its potentially fatal compression by the expanding oesophageal stent.

Prior to implantation of the stent, airway patency was restored mechanically using rigid bronchoscopes (Karl Storz GmbH, Tuttlingen, Germany) no. 6.5, 7.5 and 8.5, or using argon plasma coagulation (APC) and laser (MY 40 1.3, KLS Martin GmbH \& Co. KG, Freiburg, Germany). Silicone Y-type (Demed, Mikołów, Poland) and partially covered airway self-expanding metal stents (PCASEMS) (Ultraflex, Boston Scientific, Natick, USA) were used (Photos $1 \mathrm{~A}-\mathrm{C}$ ). The implantation of the $Y$ type prosthesis was performed using Freitag forceps, while the self-expanding oesophageal stent was applied under endoscopic control $[1-3,8,9]$.

Oesophageal stenting was performed next. Endoscopically, the stenosis was identified and dilated using the 8-10 Fr Savary-Gilliard dilators (Cook). After dilatation, the length of the involved oesophageal segment was determined using a fibreoptic endoscope, and the oesophageal prosthesis was

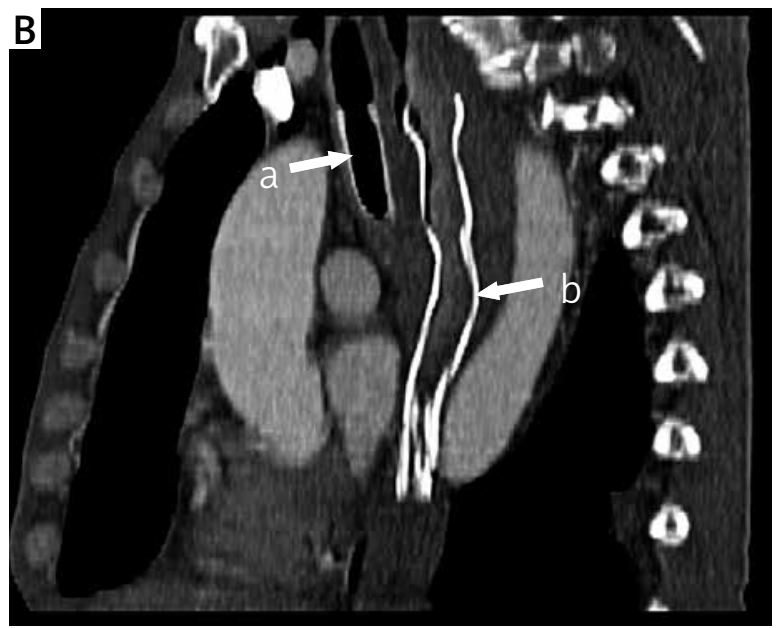

Photo 1 A-C. Computed tomography scan multiplanar reconstruction after oesophageal and airway stenting ( $\mathrm{a}$ - silicone Y-prosthesis, $\mathrm{b}$ - oesophageal prosthesis) 
introduced. Only partially covered oesophageal self-expanding metal stents (PCESEMS) (Ultraflex, Boston Scientific, Natick, USA) were used. The length of the stent was chosen with the assumption that the proximal and distal end of the prosthesis should be situated $3-4 \mathrm{~cm}$ from the fistula, and the diameter of the stent was 18 or $20 \mathrm{~mm}$. After expansion of the stent, its position was checked endoscopically.

\section{Follow-up}

Routinely, follow-up chest radiogram was obtained on the next day. On the first day after the procedure dyspnoea and dysphagia scores were assessed.

The follow-up period ranged between 1 and 169 days. Patients were evaluated on the first day after surgery and every 30 days thereafter. If the follow-up check on site was not feasible, patients were interviewed by phone. During the follow-up visit the patients' general condition, dysphagia, and dyspnoea were assessed.

\section{Statistical analysis}

Statistical analysis was performed by means of the Statistica 10 PL software package (StatSoft, USA). The following tests were used: Gehan-Wilcoxon's, Kruskal-Wallis, and the dependent variety regression test, before and after surgery. The analysis concerned gender, survival, respiratory function, dysphagia, weight loss, Karnofsky score, the use of adjuvant chemotherapy and/or radiotherapy. $P$-value $<0.05$ was considered as statistically significant.

\section{Results}

\section{Patients' characteristics}

Twenty-nine patients with oesophageal squamous cell carcinoma and 2 patients with bronchial squamous cell carcinoma were included. Two patients required emergency stenting, while the remainder underwent elective procedures. All patients presented with dyspnoea, dysphagia, weight loss ranging between 7 and $35 \mathrm{~kg}$ (mean: $7.16 \mathrm{~kg}$ ), cough and general weakness. The mean degree of bronchial stenosis was $45.3 \%$ (range: $30-70 \%$ ). Mean length of oesophageal stenosis was $5.8 \mathrm{~cm}$ (range: 3-12 cm). Diagnosis was as follows: type I fistula in 5, type II in 9, and type III in 17 patients (Table I).

\section{Alleviation of dysphagia and dyspnoea}

Oesophageal stenting was performed using partially covered self-expanding metal stents in all patients. Bronchial stenting was performed using the Y-type silicone prostheses in 23 cases, covered self-expanding tracheal prostheses in 6 , and self-expanding bronchial prostheses in 2 patients (Table II). Additionally, 5 patients required percutaneous endoscopic gastrostomy at the same time.

Double stenting was technically successful in all patients, obtaining proper oesophageal and airway patency. Statistically significant regression of dyspnoea ( 2.43 vs. $0.27, p<0.00001)$ and dysphagia $(2.59$ vs. $0.94, p<0.00001$ ) was noted (Figures 1 and 2 ).

\section{General condition and survival}

The mean Karnofsky score improved significantly after double stenting (50.4 vs. $68.3 ; p=0.00001$ ) (Figure 3).

Mean survival time in the patient group was 68.1 days (range: 3-169). The location of the fistula had no significant influence on survival. The average survival time was 68.4 days in fistula type $1,71.8$ days in type 2 , and 66.0 days in type $3(p=0.3)$.

Adjuvant therapy (radio and/or chemotherapy) was used in 21 patients (chemotherapy in 16 and radio and chemotherapy in 5 patients) and had no influence on survival $(p=0.23)$. There was no significant difference considering weight gain before and after stenting $(-7.86$ vs. $-0.48 \mathrm{~kg}, p=0.087)$ or influence of BMI on survival, $p=0.17$ (Table II).

\section{Complications}

\section{Minor complications}

Nineteen patients complained of mild pain or discomfort in the chest after stenting, lasting 1-4 days and requiring analgesics. In 2 cases, full expansion of the stent was delayed up to $48 \mathrm{~h}$. Four patients complained of difficulties in swallowing associated with a feeling of a foreign body, lasting for 3 days after oesophageal prosthesis implantation. Eleven patients required bronchoscopy during the postoperative period, due to secretion retention in the bronchial tree.

\section{Major complications}

Massive, fatal bleeding occurred in 1 patient on the third day after stenting. 
Table II. Clinical characteristics of patients before and after double stenting

\begin{tabular}{|c|c|c|c|c|c|}
\hline \multirow[t]{2}{*}{ Parameter } & \multirow[t]{2}{*}{ Mean (range) } & \multicolumn{3}{|c|}{ Type of fistulas } & \multirow[t]{2}{*}{$P$-value } \\
\hline & & Type I & Type II & Type III & \\
\hline Patients & 31 & 5 & 9 & 17 & \\
\hline \multicolumn{6}{|l|}{ Mean degree of dyspnoea (range): } \\
\hline Before stenting & $2.43(0-3)$ & $2.4(2-3)$ & $2.0(2-2)$ & $2.9(2-3)$ & $<0.00001$ \\
\hline After stenting & $0.34(0-1)$ & $0.6(0-1)$ & $0(0-1)$ & $0.29(0-1)$ & \\
\hline \multicolumn{6}{|c|}{ Mean degree (range) of stricture in airway: } \\
\hline Before stenting & $45 \%(30-70 \%)$ & $46 \%(40-50 \%)$ & $40 \%(30-50 \%)$ & $50 \%(30-70 \%)$ & $<0.00001$ \\
\hline After stenting & & 0 & 0 & 0 & \\
\hline \multicolumn{6}{|l|}{ Mean degree of dysphagia (range): } \\
\hline Before stenting & $2.59(0-3)$ & $2.6(1-3)$ & $2.66(1-3)$ & $2.52(0-3)$ & $<0.00001$ \\
\hline After stenting & $0.94(0-1)$ & $1.0(0-1)$ & $1.0(1-0)$ & $0.94(0-1)$ & \\
\hline \multicolumn{6}{|l|}{ Mean weight loss (range) [kg]: } \\
\hline Before stenting & $7.86(0-20)$ & $6.0(0-12)$ & $8.32(4-15)$ & $9.28(3-20)$ & 0.87 \\
\hline After stenting & $-0.48(0-8)$ & $+1(2-3)$ & $2.44(0-11)$ & $0(0-8)$ & \\
\hline \multicolumn{6}{|l|}{ Mean BMI (range) [kg/m²]: } \\
\hline Before stenting & 19.66 & $\begin{array}{c}20.1 \\
(18.59-23) \\
\end{array}$ & $\begin{array}{c}22.1 \\
(16.37-28.68) \\
\end{array}$ & $\begin{array}{c}16.8 \\
(16.1-20.7) \\
\end{array}$ & 0.17 \\
\hline After stenting & 19.13 & $\begin{array}{c}20.6 \\
(18.38-22.32) \\
\end{array}$ & $\begin{array}{c}19.8 \\
(15.7-28.68) \\
\end{array}$ & $\begin{array}{c}17.0 \\
(16.5-20.6) \\
\end{array}$ & \\
\hline \multicolumn{6}{|l|}{ Mean Karnofsky score (range): } \\
\hline Before stenting & $50.4(40-70)$ & $52.2(50-60)$ & $52.2(40-60)$ & $46.8(40-70)$ & 0.00001 \\
\hline After stenting & $68.3(50-70)$ & $68(60-70)$ & $65.5(50-70)$ & $70.6(50-70)$ & \\
\hline \multicolumn{6}{|l|}{ Cause of death: } \\
\hline Cachexia & & 3 & 4 & 11 & \\
\hline Dyspnoea & & 1 & 2 & 3 & \\
\hline Haemorrhage & & 1 & 3 & 4 & \\
\hline Mean survival time (range) [days] & 67.1 & $68.4(30-168)$ & $71.8(25-169)$ & $66(3-178)$ & 0.3 \\
\hline
\end{tabular}

In 1 patient with oesophago-pericardial fistula and pericardial tamponade, massive bleeding occurred during restoration of the patency of the left main bronchus, and the patient required mechanical ventilation for $10 \mathrm{~h}$. He survived 30 days after implantation of the Y-type bronchial stent, and 329 days after the diagnosis of the oesophago-pericardial fistula.

\section{Re-interventions}

In the analysed group, re-interventions were necessary in 6 (19\%) patients. They are briefly discussed below.

In 1 patient with oesophago-mediastinal fistula and compression of the tracheal bifurcation, in whom double stenting was initially performed, oesophago- bronchial fistula occurred on the $53^{\text {rd }}$ day after the procedure with oesophageal prosthesis translocation. Re-stenting was performed, and percutaneous endoscopic gastrostomy (PEG) was performed. The patient survived 113 days after re-stenting.

In the second patient, oesophago-tracheal fistula developed 35 days after bilateral stenting. A second oesophageal prosthesis was implanted and the patient died 5 days later.

In the third patient, fistula progression and prosthesis translocation was diagnosed on the $28^{\text {th }}$ day after double stenting for the oesophago-tracheal fistula. The oesophageal stent was removed, followed by re-stenting and PEG implantation. The patient survived for 24 days. 
In the fourth patient, who underwent double stenting for an oesophago-bronchial fistula, obliteration of the tracheal prosthesis by inflammatory granulation was diagnosed during the follow-up bronchoscopy on the $20^{\text {th }}$ day after stenting. During patency restoration the patient developed pneumothorax requiring pleural cavity drainage. He died after 28 days.

In the fifth patient oesophageal prosthesis migration occurred on the $10^{\text {th }}$ day after double stenting for an oesophago-mediastinal fistula. Re-stenting and PEG implantation were performed. The patient survived for 38 days.

In the sixth patient, in whom oesophago-tracheal fistula was diagnosed 451 days after oesophageal stenting for unresectable squamous-cell carcinoma, tracheal PCASEMS was implanted. Fifty-eight days later the patient was re-admitted due to increasing dyspnoea and food aspiration. The tracheal PCASEMS was removed and a silicone Y-type stent and PEG were implanted. Oral and gastrostomy nutrition was resumed and the patient was discharged from the hospital on the $7^{\text {th }}$ day after the procedure. He survived 169 days after oesophago-tracheal fistula diagnosis.

\section{Discussion}

Oesophago-respiratory fistula is a severe complication of advanced oesophageal or bronchial carcinoma. Its occurrence is estimated at $0.9-18 \%$, resulting from the direct neoplastic infiltration and necrosis between the oesophagus, bronchi and mediastinum [10]. Analysis performed at the Memorial Sloan-Kettering Cancer Center in New York, during the period between 1926 and 1988, showed the presence of fistulas in 184 (4.5\%) of 3,543 patients with oesophageal cancer. Duke University Medical Center data analysis, considering 2,440 patients diagnosed with oesophageal carcinoma, showed its occurrence in $0.9 \%$ of cases $[11,12]$.

Double stenting of the oesophagus and bronchial tree is the gold standard of treatment. The above-mentioned procedure is recommended by the American College of Chest Physicians [13], as well as the National Comprehensive Cancer Network (NCCN) [14].

Introduction of self-expanding oesophageal and airway stents as well as silicone Y-stents enables simultaneous, double stenting in patients with a malignant oesophago-airway fistula. There is a wide spectrum of self-expanding oesophageal stents available,

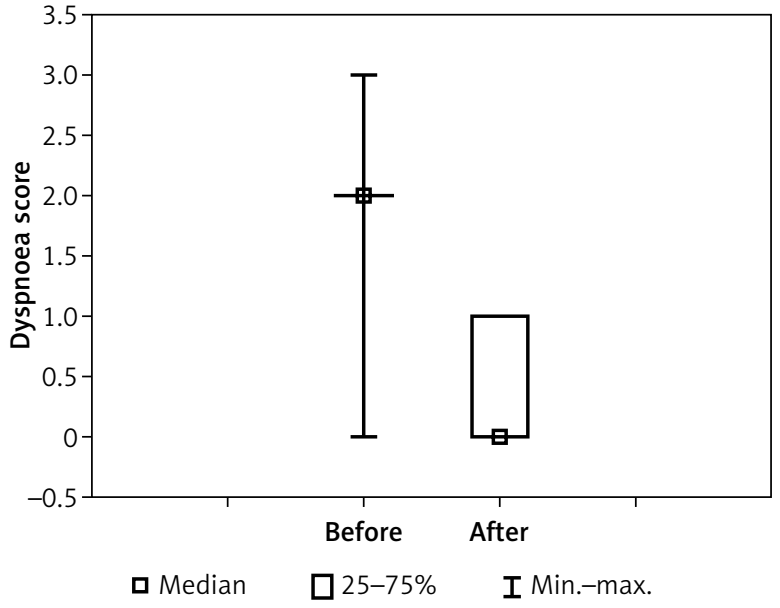

Figure 1. Dyspnoea before and after airway stenting

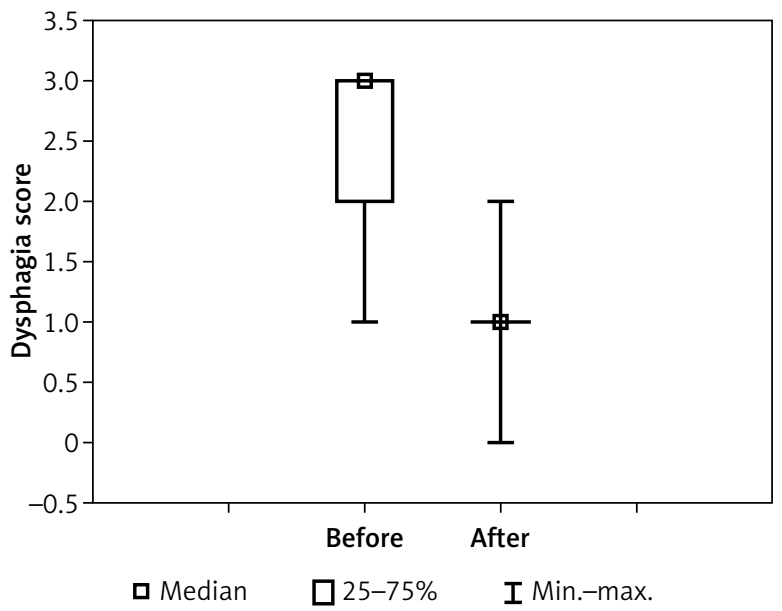

Figure 2. Dysphagia before and after stenting of the oesophagus

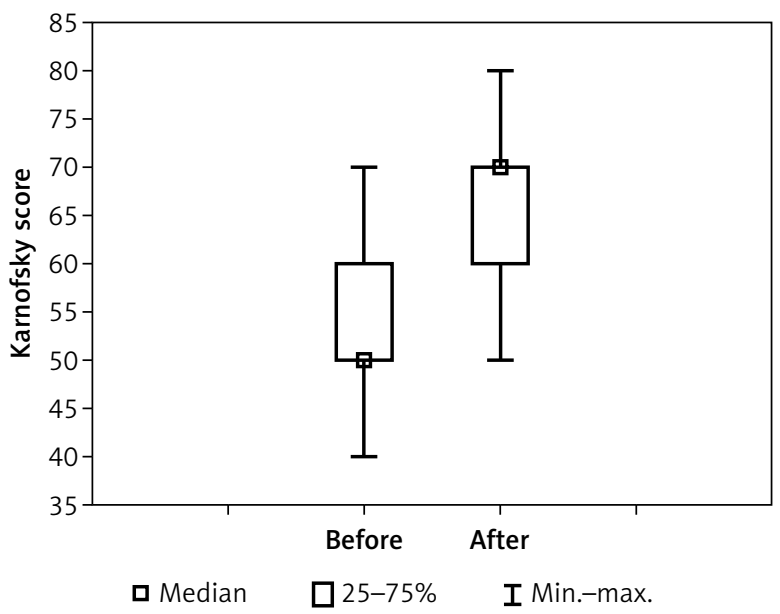

Figure 3. Quality of life before and after stenting 
including fully and partially covered stents. These stents are characterised by a nearly $100 \%$ technical success rate, a migration rate of $10-20 \%$ and mortality below 5\% [15]. The authors prefer partially covered stents, associated with low risk of migration and simplicity of precise implantation with endoscopic control only, but on the other hand with a risk of tissue ingrowth in the uncovered ends of the stent.

For the airway, the authors prefer the silicone Y-stents or, depending of the location of stenosis, self-expanding metallic airway stents.

The introduction of a silicone Y-type prosthesis and PCASEMS and PCESEMS significantly reduced the rate of complications $[4,15]$.

Double stenting enables the patient to breathe normally, facilitates oral nutrition, and improves the quality of life. The effectiveness of stenting has been demonstrated in many papers [16-19]. However, these procedures are associated with intra-, peri-, and postoperative complications [8, 20, 21]. The most feared is massive bleeding associated with bronchial tree patency restoration, which occurs in $4-27 \%$ of patients, and the risk is highest for emergency management $[9,17,18]$. Massive bleeding might occur intraoperatively, but also after that, even in long-term follow-up. In the analysed group, massive bleeding was the cause of death of 1 patient on the third postoperative day, and in 6 patients within the long-term follow-up. To minimise the risk of bleeding, these procedures should be performed in reference centres by an experienced team. Binkert and Peterson also mentioned the occurrence of early massive bleeding and patient death after bilateral stenting, when non-covered metallic prostheses were used [20]. Yakami et al. reported the occurrence of fatal bleeding as a result of atrial damage after oesophageal stenting and adjuvant radiotherapy [21]. The second most frequent serious complication is respiratory failure requiring mechanical ventilation. Herth et al. [22] noted its occurrence in $7(12 \%)$ patients. In our study group it was observed in $2(7.9 \%)$ of 26 patients.

Other severe complications are instrumental damage to the bronchi, which reportedly occurs in $2 \%$ [5] of patients.

An oesophageal fistula is always considered as a poor prognostic factor. Freitag et al. analysed data obtained from 30 patients with bronchial fistulas, demonstrating mean survival of 110 days in the case of bilateral stenting, and only 24 days in the case of unilateral (airway) stenting [8]. Herth et al. reported the mean survival time of 236.6 days in a group in which 65 patients underwent bronchial stenting, 37 underwent oesophageal stenting, and 10 underwent bilateral stenting. Longer survival was observed after oesophageal and bilateral stenting. Also the location of the fistula had an impact on survival, with right bronchial fistula being associated with the shortest survival [22]. Our observations are consistent with those of Herth et al. showing that patients with type II fistulas lived longer than patients with type III fistulas.

Double stenting itself might be the cause of an oesophageal fistula, due to necrosis of the membranous trachea. Thus, it is recommended to use covered metallic prostheses to the oesophagus without prophylactic stenting of the bronchial tree [23]. Such an approach, however, may be associated with increased risk of airway compression with acute, life-threatening impairment of ventilation. In patients included in our study, nitinol PCESEMS and PCASEMS were used. The uncovered ends of such prostheses limit the risk of migration, although obstruction due to granulation tissue overgrowth may occur. In such cases, these prostheses can be relatively easily implanted one into another without the need of their removal.

Due to disease progression, 4 (15\%) of our patients required re-intervention because of fistula recurrence. The cause of recurrence may be associated with disease progression, as well as previous stenting, which can lead to compression and necrosis of the tissue between both prostheses. Those patients were once again scheduled for re-stenting with satisfactory results.

In a group of patients after stenting and adjuvant therapy, fistula may recur in more than half of the patients [23-25]. These patients are usually in poor general condition, and re-intervention requires an experienced team. Considering our study group, mortality was not observed after re-intervention, although 1 patient developed respiratory insufficiency requiring mechanical ventilation. Survival after re-stenting ranged between 5 and 169 days (mean: 54.1 days).

In some patients, in whom full coverage of nutritional requirements is not expected, PEG should be considered. In the analysed group, PEG was performed in 5 patients.

The use of adjuvant chemotherapy remains controversial, as some reports present disease progres- 
sion with fistula development. On the other hand, chemotherapy may lead to fistula closure [23-25]. Hamai et al. [25] reported a mean survival time of 103 days, survival being longer in patients who received adjuvant therapy. Herth et al. demonstrated that the introduction of chemotherapy and/or radiotherapy is a poor prognostic factor of survival [22]. In our study, patients did not benefit from adjuvant therapy. Fifteen patients subjected to adjuvant chemo- and/or radiotherapy did not benefit, and showed no weight gain.

Double stenting is an effective and relatively safe palliative procedure, which improves the quality of life of patients with an oesophago-respiratory fistula. These patients are usually in poor general condition, with progressive dysphagia, significant weight loss, and increasing respiratory insufficiency. Stenting should be performed in a reference centre, by an experienced team capable of dealing with potential complications.

\section{Conflict of interest}

The authors declare no conflict of interest.

\section{References}

1. Stephens KE, Wood DE. Bronchoscopic management of central airway obstruction. J Thorac Cardiovasc Surg 2000; 119: 289-95.

2. Madeya S, Borsch G. Upper intestinal endoscopy in 188 bronchial cancer patients and 118 breast cancer patients with abdominal symptoms. Med Klin 1992; 15: 631-6.

3. Bolliger CT, Probst R, Tschopp K, et al. Silicone stents in the management of inoperable tracheobronchial stenoses. Indications and limitations. Chest 1992; 104: 1653-9.

4. Dumon JF. A dedicated tracheobronchial stent. Chest 1990; 97 328-32.

5. Sihoe AD, Wan IP, Yim AP. Airway stenting for unresectable esophageal cancer. Surg Oncol 2004; 13: 17-25.

6. Blazeby JM, Williams MH, Brookes ST, et al. Quality of life measurement in patients with oesophageal cancer Gut 1995; 37: 505-8.

7. Karnofsky DA, Abelmann WH, Craver LF, Burchenal JH. The use of nitrogen mustards in the palliative treatment of cancer. Cancer 1948; 1: 634-56.

8. Freitag L, Tekolf E, Steveling H, et al. Management of malignant esophagotracheal fistulas with airway stenting and double stenting. Chest 1996; 110: 1155-60.

9. Wong AYC, Lawmin JC, Irwin MG. Anesthetic management of a patient with low tracheal obstruction requiring placement of a T-Y stent. Anesth Intensive Care 2000; 28: 196-8.

10. Chan KPW, Eng P, Hsu AAL, et al. Rigid bronchoscopy and stenting for esophageal cancer causing airway obstruction. Chest 2002; 122: 1069-72.
11. Burt M, Diehl W, Martini N, et al. Malignant esophagorespiratory fistula: management options and survival. Ann Thorac Surg 1991; 52: 1222-8.

12. Postlehwait RW. Surgery of the esophagus. Appleton-Century Crofts, New York 1979; 35.

13. Kvale PA, Simoff M, Prakash UB. Lung caner. Palliative care. Chest 2003; 123: 284-311.

14. National Comprehensive Cancer Network Guidelines for the treatment of esophageal cancer 2015.

15. Verschuur EM, Steyerberg EW, Kuipers EJ, et al. Effect of stent size on complications and recurrent dysphagia in patients with esophageal or gastric cardia cancer. Gastrointest Endosc 2007; 65: 592-601.

16. Van den Bongard H, Boot H, Baas P, et al. The role of parallel stent insertion in patients with esophagorespiratory fistulas. Gastrointest Endosc 2002; 55: 110-5.

17. Paganin F, Schouler L, Cuissard L, et al. Airway and esophageal stenting in patients with advanced esophageal cancer and pulmonary involvement. Plos One 2008; 3: e3101.

18. Lecleire S, Antonietti M, Fiore D, et al. Double stenting of oesophagus and airways in palliative treatment of patients with oesophageal cancer is efficient but associated with a high morbidity. Aliment Pharmacol Ther 2007; 25: 955-63.

19. De Olabozal J, Roberts J, Hoeltgen T, et al. Double stenting to prevent airway compression in proximal malignant strictures. Am J Gastroenterol 2001; 96: 2800-1.

20. Binkert CA, Peterson BDT. Two fatal complications after parallel tracheo-esophageal stenting. Cardiovasc Intervent Radiol 2002; 25: 144-7.

21. Yakami M, Mitsumori M, Sai H, et al. Development of severe complications caused by stent placement followed by definitive radiation therapy for T4 esophageal cancer. Int J Clin Oncol 2003; 8: 395-8.

22. Herth FJ, Peter S, Baty F, et al. Combined airway and oesophageal stenting in malignant airway-oesophageal fistulas: a prospective study. Eur Respir J 2010; 36: 1370-4.

23. Nomori H, Horio H, Imazu Y, et al. Double stenting for esophageal and tracheobronchial stenoses. Ann Thorac Surg 2000; 70: 1803-7.

24. Park JY, Shin JH, Song HY, et al. Airway complications after covered stent placement for malignant esophageal stricture: special reference to radiation therapy. AJR Am J Roentgenol 2012; 198: 453-9.

25. Hamai Y, Hihara J, Emi M, et al. Airway stenting or malignant respiratory complications in esophageal cancer. Anticancer Res 2012; 32: 1785-90.

Received: 10.04.2016, accepted: 22.05.2016. 